\title{
The Utilization and Diagnostic Yield of Upper Endoscopy for Evaluation of Gastrointestinal Symptoms Within the First Year After Liver Transplantation
}

\author{
Ebubekir Daglilar ${ }^{1}$, Sean E. Connolly ${ }^{2}$, Veysel Tahan ${ }^{1}$, Ari Cohen ${ }^{3}$, George Therapondos ${ }^{4}$ \\ 1. Gastroenterology and Hepatology, University of Missouri-Columbia, Columbia, USA 2. Gastroenterology and \\ Hepatology, Ochsner Medical Center, New Orleans, USA 3. Surgery, Ochsner Medical Center, New Orleans, USA 4. \\ Gastroenterology, Ochsner Medical Center, New Orleans, USA
}

Corresponding author: Ebubekir Daglilar, edaglilar@health.missouri.edu

\section{Abstract \\ Background}

Gastrointestinal (GI) symptoms impact quality of life and increase health care utilization after liver transplantation (LTx). Esophagogastroduodenoscopy (EGD) is commonly used to investigate these symptoms.

\section{Aims}

The aim of this study was to investigate the diagnostic yield and utilization of EGD after LTx for common GI symptoms.

\section{Methods}

This single-center retrospective cohort study was conducted at a large liver transplant center and included all adults who underwent EGD within the first year after receiving LTx between January 1, 2015, and December 31, 2016. Biliary procedures were excluded.

\section{Results}

Of 437 patients who underwent LTx during the study period, 64 (15\%) underwent EGD for the evaluation of GI symptoms within the first year of transplantation. After applying exclusion criteria, 57 (13\%) cases were analyzed. GI hemorrhage (hematemesis/melena) was the most common reason $(4 \% ; n=18)$ for evaluation with EGD followed by nausea/anorexia (3\%; $n=12)$. Symptoms were investigated with EGD, including epigastric/abdominal pain $(2 \% ; n=9)$, dysphagia/odynophagia $(2 \% ; n=8)$, anemia $(1 \% ; n=5)$, diarrhea $(1 \%$; $\mathrm{n}=4)$, and heartburn $(0.2 \% ; \mathrm{n}=1)$. The diagnostic yield of EGD was highest with GI hemorrhage (83\%)

Review began 10/22/2020 Review ended 10/25/2020 Published 11/04/2020

\section{() Copyright 2020}

Daglilar et al. This is an open access article distributed under the terms of the Creative Commons Attribution License CC-BY 4.0., which permits unrestricted use, distribution, and reproduction in any medium, provided the original author and source are credited. followed by dysphagia/odynophagia (75\%). EGD diagnostic yield was lower for the other symptoms, ranging from $0 \%$ to $25 \%$.

\section{Conclusions}

EGD was commonly utilized within the first year of LTx, with the highest diagnostic yields for GI hemorrhage and dysphagia/odynophagia. Because of the low diagnostic yield of EGD for other symptoms, we recommend a careful selection of patients for EGD following LTx.

Categories: Gastroenterology, Transplantation

Keywords: liver transplantation, endoscopy, post liver transplant gastrointestinal problems, posttransplant bleeding, posttransplant anorexia

\section{Introduction}

Liver transplantation (LTx) is a life-saving surgery for patients with end-stage liver disease, hepatocellular carcinoma, and other metabolic diseases of the liver [1]. Survival outcomes at one and five years posttransplantation are excellent [2], but LTx is associated with significant surgical and postsurgical complications [3]. The average age of transplant recipients has been increasing [4], and recipients often have several comorbidities including cardiac, pulmonary, renal, and gastrointestinal (GI) illnesses that can complicate postoperative recovery, decrease quality of life [5], and increase health care utilization [6]. Biliary complications, including strictures and bile leaks, are common (with an incidence of 10\%-25\%) but can be safely and effectively managed with endoscopic interventions [7]. Aside from biliary complications, GI symptoms include GI bleeding [8] and nausea/anorexia, which can lead to malnutrition [9] and prolonged postoperative recovery [10]. Immunosuppression following transplantation increases the risk of infectious 
complications that can involve the entire GI tract and lead to symptoms of dysphagia/odynophagia, epigastric/abdominal pain, and diarrhea [11]. Esophagogastroduodenoscopy (EGD) is commonly used to investigate GI symptoms. Our study aimed to determine the utilization and diagnostic yield of EGD for common GI symptoms after LTx.

\section{Materials And Methods}

Institutional Review Board approval was obtained prior to data collection. The requirement for informed consent was waived given the retrospective nature of the study. All data were collected retrospectively at a large liver transplant center (Ochsner Multi-Organ Transplant Institute, New Orleans, Louisiana, USA) from the electronic health record. All adults who underwent EGD within the first year after receiving deceased donor LTx between January 1, 2015, and December 31, 2016, were included in the study. Patients younger than 18 years of age, those who underwent biliary procedures (endoscopic ultrasound [EUS], endoscopic retrograde cholangiopancreatography [ERCP], or biliary stent removal with EGD), and living donor recipients were excluded. The following data were collected: patient age, gender, LTx date, and indications for the procedures. EGDs were performed by board-certified gastroenterologists with the American Society of Gastrointestinal Endoscopy quality metrics. Esophagitis was graded based on the Los Angeles (LA) classification system. Endoscopic findings such as LA grade A esophagitis and mild gastric/duodenal erythema with negative biopsies for Helicobacter pylori or viral stains were interpreted/reported as negative studies. All patients underwent EGD for the evaluation of nausea/anorexia, and biopsies from the stomach and duodenum were also obtained. All biopsies were stained for $H$. pylori, viral, or fungal stains as deemed appropriate. Descriptive analysis was used to report findings of the study.

\section{Results}

Among the 437 patients who underwent LTx, 64 (15\%) underwent EGD for the evaluation of GI symptoms within the first year of LTx. Among these, seven cases met the exclusion criteria (stent removal $[\mathrm{n}=4]$, variceal surveillance [n=2; EGD showed resolution of varices], follow-up of a previously known duodenal polyp [n=1]); therefore, 57 (13\%) patients were included in the analysis.

Relative to the entire cohort of LTx patients, 18 (4\%) patients underwent EGD for evaluation of GI hemorrhage (including hematemesis or melena). The endoscopic diagnoses were portal hypertensive gastropathy $(n=4)$, gastric ulcer $(n=4)$, duodenal ulcer $(n=3)$, LA grade $D$ esophagitis $(n=1)$, esophageal ulcer $(\mathrm{n}=1)$, arteriovenous malformation $(\mathrm{n}=1)$, and Dieulafoy lesion $(\mathrm{n}=1)$. EGD did not reveal any source of bleeding in three patients.

Nausea/anorexia (3\%) was the second most common reason for investigation with EGD $(n=12)$. EGD was normal for nine patients but showed LA grade C/D esophagitis in two patients and gastric ulcer in one patient. Three $(0.7 \%)$ patients who had anorexia and prolonged nausea underwent percutaneous endoscopic gastrostomy tube placement.

Epigastric/abdominal pain was investigated in nine (2\%) patients, and EGD revealed mild gastric/duodenal erythema in seven patients. Two studies were normal. In the patients with mild erythema in the stomach or duodenum, biopsies obtained for pathologic examination, $H$. pylori immunohistochemical testing, and viral stains were negative in all cases.

Dysphagia/odynophagia was investigated in eight cases (2\%), and EGD revealed LA grade C or D esophagitis $(n=4)$, ischemic esophagitis $(n=1)$, and esophageal candidiasis $(n=1)$. Two studies were normal.

EGD was performed for the evaluation of anemia in five (1\%) cases, which revealed portal hypertensive gastropathy in one case and normal in four cases. Diarrhea was the reason for EGD in four (1\%) patients. Three studies were normal; one study revealed villous atrophy. One patient underwent evaluation of heartburn with normal EGD findings. EGD findings are summarized in Table 1. 


\section{Cureus}

\begin{tabular}{|c|c|c|}
\hline $\begin{array}{l}\text { Reason for upper } \\
\text { endoscopy }\end{array}$ & $\begin{array}{l}\text { Number of } \\
\text { LTx } \\
\text { recipients } \\
(n=57)\end{array}$ & Endoscopy findings \\
\hline $\begin{array}{l}\text { Gastrointestinal } \\
\text { hemorrhage } \\
\text { (hematemesis/melena) }\end{array}$ & 18 & $\begin{array}{l}\text { Portal hypertensive gastropathy }(n=4) \text {, gastric ulcer }(n=4) \text {, duodenal ulcer }(n=3) \text {, LA grade } \\
\text { D esophagitis }(n=1) \text {, esophageal ulcer }(n=1) \text {, arteriovenous malformation }(n=1) \text {, Dieulafoy } \\
\text { lesion }(n=1) \text {, normal }(n=3)\end{array}$ \\
\hline Nausea/anorexia & 12 & LA grade C/D esophagitis $(n=2)$, gastric ulcer $(n=1)$, normal $(n=9)$ \\
\hline $\begin{array}{l}\text { Epigastric/abdominal } \\
\text { pain }\end{array}$ & 9 & Mild gastric/duodenal erythema* $(n=7)$, normal $(n=2)$ \\
\hline Dysphagia/odynophagia & 8 & $\begin{array}{l}\text { LA grade } C / D \text { esophagitis }(n=4) \text {, ischemic esophagitis }(n=1) \text {, esophageal candidiasis }(n=1) \text {, } \\
\text { normal }(n=2)\end{array}$ \\
\hline $\begin{array}{l}\text { Anemia without overt } \\
\text { bleeding }\end{array}$ & 5 & Portal hypertensive gastropathy ( $n=1)$, normal $(n=4)$ \\
\hline Diarrhea & 4 & Villous atrophy $(n=1)$, normal $(n=3)$ \\
\hline Heartburn & 1 & Normal $(n=1)$ \\
\hline
\end{tabular}

\section{TABLE 1: Summary of esophagogastroduodenoscopy findings}

*All biopsied and tested negative for Helicobacter pylori and viral inclusions.

LA, Los Angeles; LTx, liver transplantation

Diagnostic yield of EGD was highest for GI hemorrhage (83\%) followed by dysphagia/odynophagia (75\%). EGD had lower diagnostic yields for all other symptoms (Figure 1).

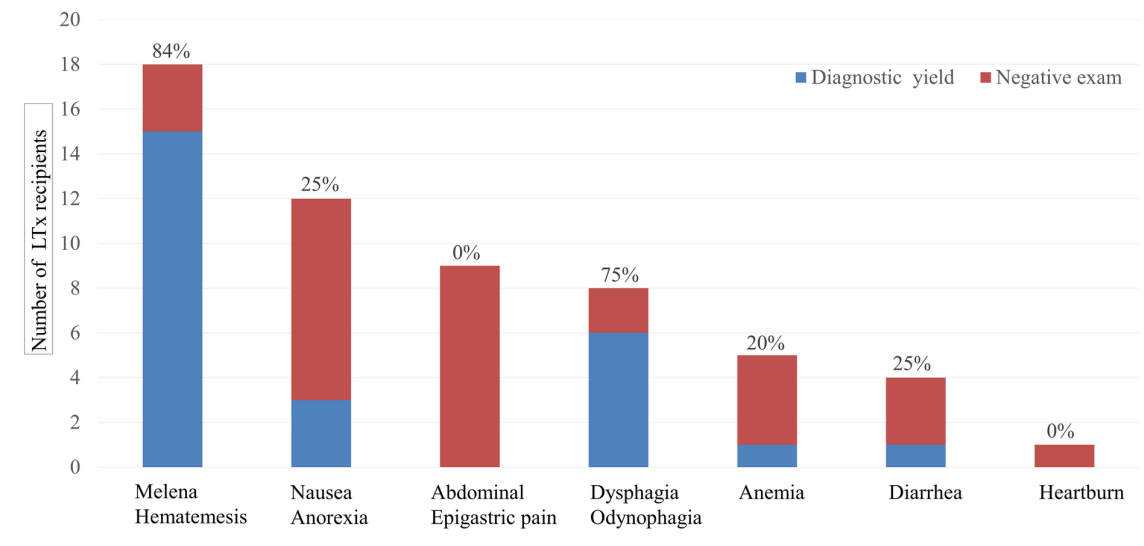

FIGURE 1: The utilization and diagnostic yield of EGD within the first year of LTX

EGD, esophagogastroduodenoscopy; LTx, liver transplantation

\section{Discussion}

LTx outcomes have been improving with the advances in the liver transplant field [12], but clinicians encounter frequent posttransplant-related GI problems and complications [4]. Many studies have focused on complications of surgical [13], biliary [7], infectious [11], and vascular diseases [14], but we examined the role and yield of EGD for non-biliary GI complications. 
During the two-year study period, 437 consecutive deceased donor LTx recipients were included. Within the first year of LTx, 57 (13\%) patients underwent EGD. Of our LTx patients, 4\% underwent EGD for the evaluation of GI hemorrhage (including hematemesis or melena). No mortality was related to the GI bleeding episodes identified in our population, but they resulted in additional days of hospital stay or readmissions. The etiology of the GI bleeding in our cohort was similar to that in the non-transplant population [15], with the most common finding being peptic ulcer disease in seven cases and portal hypertensive gastropathy in four cases. Akatsu et al. reported rapid and complete resolution of portal hypertension and related complications following living donor LTx, whereas peptic ulcer disease was reported to be as high as $6.9 \%$ [16]. In our cohort, the rate of peptic ulcer disease was $2 \%$. The high incidence of peptic ulcer disease in Akatsu et al.'s study was likely related to the use of histamine 2 receptor antagonist medications instead of proton pump inhibitors (PPIs) following LTx. In our cohort, five (1\%) patients had refractory portal hypertension resulting in bleeding or anemia. In this group, EGD was performed two weeks to three months after LTx. The prevalence of post-LTx portal hypertension has been reported as high as $2.8 \%$, resulting in variceal bleeding or ascites [17]. Doppler ultrasound evaluation is recommended for the diagnosis of portal hypertension in patients with ongoing bleeding following LTx. Hanouneh et al. reported recurrent GI bleeding masquerading as gastric variceal bleeding on EGD following living donor LTx [8], but subsequent imaging studies showed that bleeding was due to prominent submucosal gastric artery as a complication of splenic artery ligation during surgery. It is vital to differentiate these two conditions as cyanoacrylate treatment of this lesion can result in significant systemic embolization. Other causes of bleeding were severe esophagitis with LA grade D, arteriovenous malformation, and a Dieulafoy lesion. All of the bleeding cases in our cohort were effectively treated with endoscopic hemostasis techniques.

In the majority of the patients with nausea/anorexia, the underlying cause was deemed multifactorial and included postoperative narcotics use, polypharmacy, periprocedural infections, or gastroparesis. In the postoperative period, several risk factors have been proposed for the development of nausea, including anesthesia technique, duration of anesthesia, opioid administration, and patient-related factors [10]. In all 12 cases of nausea/anorexia, biopsies were obtained from the stomach or small bowel for pathological examination, but none were positive for $\mathrm{H}$. pylori or viral inclusions. Although we did not see any viral gastritis cases, Nohr et al. reported a case of Varicella-zoster virus gastritis post-LTx, who also had skin manifestations and systemic involvement, and was successfully treated by antiviral agents [18].

In contrast to several studies reporting prevalence rates of $H$. pylori in patients with end-stage liver disease of 50\% pretransplant and 5.6\% posttransplant [16-19], we had a zero $H$. pylori infection rate in our post-LTx patients, likely because of testing and eradication of $H$. pylori prior to LTx in our patient population.

Organ transplant recipients and patients with human immunodeficiency virus (HIV ) infection are at the highest risk for infectious esophagitis, including bacterial, viral, and fungal infections that often present as dysphagia or odynophagia [20-21]. Cytomegalovirus esophagitis is the second most common GI manifestation after cytomegalovirus colitis and has been reported in $1 \%$ of the all diagnostic endoscopies [20]; in our cohort, severe esophagitis (including LA grade C/D and ischemic esophagitis) was the most common endoscopic finding for dysphagia/odynophagia followed by esophageal candidiasis. No cases of viral esophagitis (herpes simplex virus or cytomegalovirus) were seen, likely because of the effective use of prophylactic antiviral treatments. The one case of ischemic esophagitis was associated with multiple organ dysfunction, and a similar presentation was previously reported [22]. The patient with esophageal candidiasis was treated with appropriate antifungal agents, and the symptoms resolved.

In the patient with villous atrophy, testing for celiac disease was negative; therefore, the finding was attributed to the use of immunosuppressive medication (mycophenolate), as celiac-like enteropathy has been reported in several cases with the use of mycophenolate sodium [23].

Although Akatsu et al. reported an increased incidence of reflux esophagitis following LTx [16], we did not appreciate it in our study population. Our study group only had eight (2\%) cases of esophagitis, which may have been the result of prophylaxis with PPIs.

Our study has limitations as it represented a single-center experience with a retrospective review of medical records. Large-scale studies are needed to understand the incidence and prevalence of the GI problems following LTx. Preliminary findings of the study were presented as a poster at the American College of Gastroenterology meeting in Orlando [24].

\section{Conclusions}

Our study indicates that EGD has a major role in the definitive diagnosis and specific treatment of the GI problems developing after LTx. EGD diagnostic yield was low in our LTx patients with nausea/anorexia, abdominal/epigastric pain, diarrhea, and anemia. The highest EGD diagnostic yields were appreciated in LTx patients with GI hemorrhage and dysphagia/odynophagia symptoms that were managed with therapeutic interventions.

\section{Additional Information}




\section{Disclosures}

Human subjects: Consent was obtained by all participants in this study. Ochsner Clinic Foundation issued approval FWA00002050. Animal subjects: All authors have confirmed that this study did not involve animal subjects or tissue. Conflicts of interest: In compliance with the ICMJE uniform disclosure form, all authors declare the following: Payment/services info: All authors have declared that no financial support was received from any organization for the submitted work. Financial relationships: All authors have declared that they have no financial relationships at present or within the previous three years with any organizations that might have an interest in the submitted work. Other relationships: All authors have declared that there are no other relationships or activities that could appear to have influenced the submitted work.

\section{References}

1. Calzadilla-Bertot L, Jeffrey GP, Jacques B, et al.: Increasing incidence of nonalcoholic steatohepatitis as an indication for liver transplantation in Australia and New Zealand. Liver Transpl. 2019, 25:25-34. 10.1002/lt.25361

2. Aravinthan AD, Fateen W, Doyle AC, et al.: The impact of preexisting and post-transplant diabetes mellitus on outcomes following liver transplantation. Transplantation. 2019, 103:2523-2530. 10.1097/TP.0000000000002757

3. Hirschfield GM, Gibbs P, Griffiths WJH: Adult liver transplantation: what non-specialists need to know . BMJ. 2009, 338:1670. 10.1136/bmj.b1670

4. Durand F, Levitsky J, Cauchy F, Gilgenkrantz H, Soubrane O, Francoz C: Age and liver transplantation. J Hepatol. 2019, 70:745-758. 10.1016/j.jhep.2018.12.009

5. Weng LC, Huang HL, Lee WC, Tsai YH, Wang WS, Chen KH: Health-related quality of life of living liver donors 1 year after donation. Hepatobiliary Surg Nutr. 2019, 8:1-9. 10.21037/hbsn.2018.11.10

6. Ilyassova B, Yenin Y, Baymakhanov B, Doskhanov M: Clinical and morphologic diagnostic assessments of liver diseases after liver transplant. Exp Clin Transplant. 2018, 16:89-94. 10.6002/ect.TOND-TDTD2017.035

7. Moy BT, Birk JW: A review on the management of biliary complications after orthotopic liver transplantation. J Clin Transl Hepatol. 2019, 7:61-71. 10.14218/JCTH.2018.00028

8. Hanouneh IA, Confer BD, Zein NN, Alkhouri N, Eghtesad B: Recurrent upper gastrointestinal bleeding masquerading as gastric variceal bleeding on endoscopy after liver transplantation. Liver Transplantation. 2013, 19:926-928. 10.1002/lt.23674

9. Ganoza A, Laudano M, Girlanda R, et al.: Impact of malnutrition on outcomes after liver transplantation. Transplantation. 2014, 98:738. 10.1097/00007890-201407151-02518

10. Tateosian VS, Champagne K, Gan TJ: What is new in the battle against postoperative nausea and vomiting? . Best Pract Res Clin Anaesthesiol. 2018, 32:137-148. 10.1016/j.bpa.2018.06.005

11. Huprikar S: Update in infectious diseases in liver transplant recipients . Clin Liver Dis. 2007, 11:337-354. 10.1016/j.cld.2007.04.006

12. Adam R, Karam V, Cailliez V, et al.: 2018 Annual Report of the European Liver Transplant Registry (ELTR) 50-year evolution of liver transplantation. Transpl Int. 2018, 31:1293-1317. 10.1111/tri.13358

13. Tan-Tam C, Segedi M, Buczkowski A, et al.: Surgical complications of liver transplantation. AME Med J. 2018, 3:107-107. 10.21037/amj.2018.10.02

14. Astarcioglu I, Egeli T, Gulcu A, et al.: Vascular complications after liver transplantation [Online ahead of print]. Exp Clin Transplant. 2019, 10.6002/ect.2018.0240

15. Rotondano G: Epidemiology and diagnosis of acute nonvariceal upper gastrointestinal bleeding . Gastroenterol Clin North Am. 2014, 43:643-663. 10.1016/j.gtc.2014.08.001

16. Akatsu T, Yoshida M, Kawachi S, et al.: Consequences of living-donor liver transplantation for upper gastrointestinal lesions: high incidence of reflux esophagitis. Dig Dis Sci. 2006, 51:2018-2022. 10.1007/s10620-006-9362-3

17. Korda D, Deák PÁ, Kiss G, et al.: Management of portal hypertension after liver transplantation. Transplant Proc. 2017, 49:1530-1534. 10.1016/j.transproceed.2017.06.015

18. Nohr EW, Itani DM, Andrews CN, Kelly MM: Varicella-Zoster virus gastritis: Case report and review of the literature. Int J Surg Pathol. 2017, 25:449-452. 10.1177/1066896917696751

19. Balan KK, Jones AT, Roberts NB, Pearson JP, Critchley M, Jenkins SA: The effects of Helicobacter pylori colonization on gastric function and the incidence of portal hypertensive gastropathy in patients with cirrhosis of the liver. Am J Gastroenterol. 1996, 91:1400-1406.

20. Wang HW, Kuo CJ, Lin WR, et al.: The clinical characteristics and manifestations of cytomegalovirus esophagitis. Dis Esophagus. 2016, 29:392-399. 10.1111/dote.12340

21. O'Rourke A: Infective oesophagitis: epidemiology, cause, diagnosis and treatment options. Curr Opin Otolaryngol Head Neck Surg. 2015, 23:459-463. 10.1097/MOO.0000000000000199

22. Kim DB, Bowers S, Thomas M: Black and white esophagus: rare presentations of severe esophageal ischemia. Semin Thorac Cardiovasc Surg. 2017, 29:256-259. 10.1053/j.semtcvs.2017.01.006

23. Filiopoulos V, Sakellariou S, Papaxoinis K, et al.: Celiac-like enteropathy associated with mycophenolate sodium in renal transplant recipients. Transplant Direct. 2018, 4:375. 10.1097/TXD.0000000000000812

24. Daglilar ES, Cowley KP, Anindo M, Connolly SE, Therapondos G: The utilization and diagnostic yield of upper endoscopy for evaluation of gastrointestinal symptoms within 1-year after liver transplantation. World Congress of Gastroenterology at ACG2017 Meeting Abstracts. Orlando, FL: American College of Gastroenterology, October 17, 2017, 2295. 